\title{
Development of Computer-Aided Industrial Design Technology
}

\author{
Enes Akca \\ Department of Mechanical Engineering, Faculty of Engineering and Natural Sciences, International University of Sarajevo
}

\begin{tabular}{|c|c|}
\hline Article Info & ABSTRACT \\
\hline Article history: & With the development of science and technology, industrial design industry also \\
\hline Received Jan $23^{\text {rd }}, 2017$ & in development, and at the same time, the industrial market in the design of the \\
\hline Revised Apr 09 ${ }^{\text {th }}, 2017$ & Industry, the species diversity of interest requirement also become \\
\hline Accepted June $16^{\text {th }}, 2017$ & quality and quantity can better development, computer aided design of the \\
\hline Keyword: & $\begin{array}{l}\text { industry design. This paper puts forward based on computer aided the origin of } \\
\text { the industrial design, and then puts forward computer-aided industrial design of }\end{array}$ \\
\hline CAD & man-machine interaction of the concept and characteristic, and human- \\
\hline CAID & computer interaction application in industrial design, and finally to the future \\
\hline Industrial design techology & \\
\hline
\end{tabular}

\section{Corresponding Author:}

Enes Akca,

Departement of Mechanical Engineering,

International University of Saraejvo,

Hrasnicka cesta 15, 71210, Sarajevo, Bosnia and Herzegovina.

Email: eakca@ius.edu.ba

\section{Introduction}

For over a decade many of the Computer-Aided Design programs have been around, and the first traces of their impact begun over 50 years ago. Furthermore, some of the best known early engineering drawings were seen in the work of Leonardo da Vinci. While he is well known for his Mona Lisa, he was also a designer of military machines and forerunner of today's industrial machines. Leonardo's design work was artistic in nature, more illustration than engineering drawings. His work was quite advanced for the time, however, no multi-view drawings of any of his designs are known to exist today, so we can say that modern engineering started in 1950s and by that time there were dozens of people working on numerical control of different machines and programming engineering design [1]. After PRONTO, Sketchpad and other programs, by the 1970s, research had moved from 2D to 3D. Nowadays, modern CAD era consists of not just improvement in modeling and analysis but also from engineering, manufacturing to sales and marketing [2]. The future of CAD certainly means a combination of the accuracy and control of design with the speed and flexibility of precise modeling. The result is that designers spend less time planning a model's construction, they are more focused on waiting for the changes in design, and they spend less time in remodeling the design for future uses. Industrial technology, that is the central focus of the article, is very much supported by new discoveries within CAD, since wide variety of hardware and software is developed, and a variety of constantly changing technologies are attracting the industrial design talents as well. Computer-aided Industrial Design (CAID) is a software system that gives support to product development in form, color, decoration, and most importantly it is a tool for support in product innovation design. Industrial design is mostly based on marketing and economy, however with the development of new technologies the economy is going through changes as well. Customer's demand is primary, personalization, and originality are the key. To gain all that CAID is crucial, therefore it is emphasized how most companies face the trend of increasing competition and product complexity, so enterprises are enhancing cooperation and participate in dynamic manufacturing, were computer systems can create flexible 
and agile manufacturing mode. To give a better understanding of the topic Yao [2] introduced with the very beginnings of CAID, the influence of the design on industry, several characteristics and problems that may occur within the CAID.

\section{Effect of the Computer to Industrial Design}

Industrial design is going through an expansion and aside from frequent human-computer interaction it also requires artificial intelligence technology. In the past, there was a persistent battle between the desire to implement new software techniques and the performance of available computers. That has changed in recent years as the performance of low-cost computers had its burst. During the past 40 years, price and performance percentages of available systems have increased by a factor of a million and there is no indication that the pace is slowing down. In fact it is accelerating. Software has become much stronger and there are only few design problems that cannot be freely handled today. In the design, key process is creative design thinking, where it is crucial to create the translation of the designer's conception into drawing. That is a complex process and in the world of design it is known as the stage of concept function. Another important segment is design grammar. That is the formal description method that shapes the object and its principle by refining abstract elements of the shape. It is one of the foundations of intelligent design system. In the early days of the CAD industry, system vendors had to spend considerable effort designing basic hardware components and programming foundationlevel software functions. Today's computers come with all these capabilities built in and as a consequence CAD software vendors are able to concentrate their development resources on providing enhanced and more reliable applications. Some computers are equipped with microprocessors that contain dual or quad computing elements. We use chips with eight, sixteen or more processing elements, therefore CAD software, of course, has to be adapted to use these advanced processing capabilities. Booker [3] makes a firm statement, on the subject of the importance of computer, and its influence to the concept and method of industrial design. Since today we use computers to generate data model, difficulties that designers had in changing model into engineering drawing are gone, and the relationship between design and manufacturing is closer. Moreover, the CAD has shortened the entire product improvement cycle. On one hand, it increases the efficiency and the speed of the final product, on the other hand I believe that it eliminates the traditional performance in design, and many designers just go over the design without any previous excitement of creating something new. When it comes to product modeling, designer plans their final product on imagining what the final outcome will be, therefore, computer assisted cartography changes this concept and improves efficiency to avoid losses caused by corrupted design at the design stage. That brings us to the core of the article which is the very production and application of industrial design.

\section{Application of CAID}

CAID bring advantages for the designers since they have the freedom to express their wishes and display their creative idea. It ensures the high quality of the design through new advanced design tools that are approachable to any designer. New computer programs bring flexibility since they use high-tech tools for creative design directly on the system. Designer is able to see and implement 3D solid modeling techniques for geometric modeling of objects. They can choose a color design, form, texture, many different styles in design, and go through program evaluation and testing. It can easily be modified until the client's desires are satisfied. The system is used to optimize the design for the needs of the market. Virtual reality, neural networks, genetic algorithms and parallel design are introduced in CAID field. Currently, computer design mainly uses algorithms that include adaptive neural network and morphological differences in remaining algorithm, so that way designers are able to control the generation of the new design. Yao is stressing the fact that CAD is aside from such a huge development, a field that will go through many changes in the future. He mostly relates that with the further growth of technology. In accordance to that, industrial design will have an outbreak as well. When new technologies take their place, such as artificial intelligence, virtual reality technology etc. we must find a new way to understand the design process and the new level of thinking about design in general. CAID will make industrial design develop in the direction of expansion, integration, it will make human-computer interaction more natural, and innovative design more advanced and operative. For me one of the most interesting segments of the article was author's reference on the artificial intelligence and user interface progress. He believes that today's internet connectivity is crucial for expanding the presence of art and design space towards the broader digitization of the art design. We can be as free and say that even without internet the presence of design is guaranteed, since like Yao said in that case the constraint is purely geographical. 


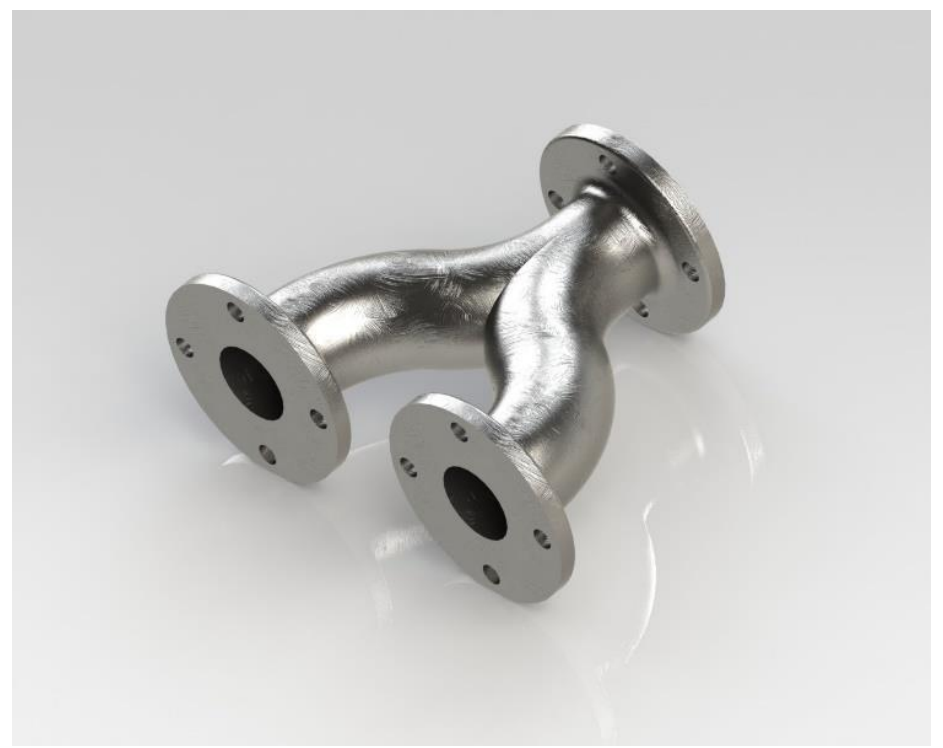

Figure 1. Computer-aided design softwere system

Electronic design is the basic aspect of computer technology and it indicates a long-term research plan based upon the insights into where the technology will allow us to go over the next decade or two. Whether we want to admit or not the development of the "New World" is beginning to show its stresses with visible changes in business practice, and the shift to multi-core processors, therefore we are witnessing early manifestations of the problems ahead. Unfortunately, much less reliable technology will follow, forcing further changes in industry, design practice, software development, and if designers are unsuccessful in fully containing these problems, we will face noticeable changes in system strength and performance. The major problem remaining is applying the technology to increasingly complex projects. That means managing enormous amounts of design data, a task some companies are doing well while others are struggling.

\section{Conclusion}

CAID is phenomenal technology that is revolutionizing engineering design and manufacturing, especially when used right, therefore it is important to allow the further growth of new designers and new ideas.

\section{References}

[1] Cianchi, Marco, Leonardo's Machines, Edizioni Becocci, Largo Liverani, Florence, Italy.

[2] YAO, Jun, International Journal of Computer Science Issues, vol. 10, no 1, January 2013.

[3] Booker, Peter Jeffrey, A History of Engineering Drawing, Chatto \& Windus 1963.

[4] Rajesh Kumar Goutam, Sanjay Kumar Dwivedi, "Search Engines Comparison on the Basis of Session Duration and Click Hits", International Journal of Computer Science Issues, vol. 8, no. 2, pp.179-183, 2011.

[5] WANG Hai-bo, "Computer Aided Industrial Design", Journal of Anhui University of Technology, no.2, pp.23-26, 2005.

[6] Johannes Behrisch, Mariano Ramirez, Damien Giurco, "Representation of Ecodesign Practice: International Comparison of Industrial Design Consultancies", Sustainability, vol. 3, no.10, pp. 1778-1791, 2011.

[7] G.L. Hu, X. Zhu, "Comprehensive evaluation of population, resources, environment and economic system of Xinjiang: Based on the principal component analysis", Ecological Economy, no. 6, pp. 67-69, 2009.

[8] S. Li, W. Qiu, and Q.L. Zhao, "Quantitative relationship between environmental quality and economic development of Heilongjiang province", Journal of Harbin Institute of Technology, vol. 38, no. 11, pp. 1986-1988, 2006. 
[9] Elmira Moghaddami Khalilzad, Sanam Hosseini, "Recovery of Faulty Cluster Head Sensors by Using Genetic Algorithm (RFGA) ", International Journal of Computer Science Issues, vol. 9, no. 4, pp. 141$145,2012$.

[10] Gert Pasman, Ingrid Mulder, "Bringing the Everyday Life into Engineering Education", International Journal of Advanced Corporate Learning, Vol. 4, No.1, pp: 25- 31, 2011.

[11] E. Akca, "The application of CFD to IUS buildings analysis", Periodicals of Engineering and Natural Sciences, vol. 4, no. 1, pp. 9-16, 2016.

[12] E. Akca, "Validation of Stresses with Numerical Method and Analytical Method", Periodicals of Engineering and Natural Sciences, vol. 4, no. 1, pp. 17-28, 2016.

\section{BIBLIOGRAPHY OF AUTHORS}

Enes Akca - Enes was born in Istanbul in 1990. He acquired his bachelor and graduate degrees from
International University of Sarajevo in Sarajevo. He employed as academic staff at International
University of Sarajevo, at the beginning of 2015, Enes is Senior Assistant at International University
of Sarajevo, Department of Mechanical Engineering, PhD candidate at the same time. He is also
serving administrative duties as Mechanical Engineering Laboratory Assistant of Research and
Development Center at International University of Sarajevo.

